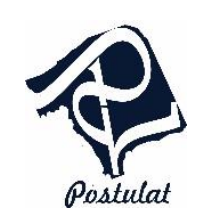

Jurnal Inovasi Pendidikan Matematika

Volume 1, Nomor 2, Desember 2020

\title{
Profil Kecepatan dan Temperatur Pada Aliran Konveksi Campuran Yang Melalui Bola Berpori Dengan Pengaruh Hidrodinamika Magnet
}

\author{
Mohamad Tafrikan', Mohammad Ghani² \\ Fakultas Sains dan Teknologi ${ }^{I}$, Universitas Islam Negeri Walisongo \\ Semarang, Jl. Walisongo No.3-5, Tambakaji, Kec. Ngaliyan, Kota Semarang, Jawa Tengah \\ 50185;tafrikan@walisongo.ac.id \\ School of Mathematics and Statistics, Northeast Normal University \\ Changchun $^{2}$; China, Jilin, Changchun, Nanguan District, 人民大街5268号; jian111@nenu.edu.cn
}

\begin{abstract}
In this paper, free convection flow and forced convection flow have important role in mixed convection flow. In this case, the effect of pressure forces and buoyant forces are significant. Mixed convection flow can be used in reactor reaction technology and electronic cooling. In this paper, the boundary layer equation for mixed convection flow of viscoelastic fluid past over the porous sphere is first transformed into non-dimension form, then transformed into non-similar form which is then numerically solved by using finite difference method Keller-Box. The numerical results obtained include velocity profile $\left(f^{\prime}\right)$, and temperature profile $(\theta)$ with the effect of maghnetohydrodynmic parameter $(M)$.

Keywords: Mixed Convection Fluid, Non-Newtonian Fluid, Viscoelastic Parameter, Keller-Box, Prandtl Number, Porosity Parameter.
\end{abstract}

\begin{abstract}
Abstrak
Pada makalah ini, aliran konveksi bebas dan aliran konveksi paksa berperan penting pada aliran konveksi campuran. Dalam hal ini, pengaruh gaya tekanan (pressure forces) dan gaya apung (buoyant forces) pada aliran konveksi bebas menjadi signifikan. Aliran konveksi campuran dapat digunakan pada teknologi reaksi reaktor dan pendingin elektronik. Dalam makalah ini, persamaan lapisan batas (boundary layer) dari aliran konveksi campuran fluida viskoelastik yang melewati permukaan sebuah bola berpori awalnya ditransformasikan kedalam bentuk non-dimensi, kemudian ditransformasikan kedalam bentuk persamaan lapisan batas nonsimilar yang diselesaikan secara numerik menggunakan metode beda hingga Keller-Box. Hasil numerik pada makalah ini adalah profil kecepatan $\left(f^{\prime}\right)$, dan profil temperatur $(\theta)$ dengan pengaruh parameter hidrodinamika magnet $(M)$.

Kata kunci: Aliran Konveksi Campuran, Fluida Non-Newtonian, Parameter Viskoelastik, Keller-Box, Bilangan Prandtl, Parameter Poros.
\end{abstract}


INFO ARTIKEL

$\begin{array}{ll}\text { ISSN } & : 2733-0597 \\ \text { e-ISSN }: & 2733-0600 \\ \text { DOI } \quad: \text { http://dx.doi.org/10.30587/postulat.vli2.2091 }\end{array}$

Submit Artikel: $\quad$ Jejak Artikel

2 Juni 2020

Submit Revisi:

1 Oktober 2020

Upload Artikel:

5 Desember 2020

\section{PENDAHULUAN}

Perpindahan panas konveksi merupakan perpindahan panas dari suatu tempat ke tempat lain yang disebabkan oleh pergerakan fluida. Konveksi panas secara garis besar dibagi menjadi dua, yaitu konveksi bebas (free convection) dan konveksi paksa (forced convection). Konveksi bebas disebabkan oleh gaya apung (buoyancy forces) karena perbedaan temperatur pada fluida. Saat fluida dipanaskan, perubahan densitas pada lapisan batas menyebabkan fluida yang dipanaskan naik dan berubah menjadi fluida yang lebih dingin, sedangkan fluida paksa atau yang disebut sebagai adveksi panas disebabkan oleh gaya luar. Saat aliran gaya pada konveksi bebas menjadi signifikan, proses tersebut disebut sebagai aliran konveksi campuran yang merupakan gabungan antara aliran konveksi bebas dan konveksi paksa. Di dalam makalah ini, pada mulanya persamaan lapisan batas ditransformasikan kedalam bentuk non-dimensi, kemudian ditransformasikan lagi kedalam bentuk non-similar yang diselesaikan secara numerik dengan menggunakan metode beda hingga Keller-Box untuk permasalahan aliran konveksi campuran fluida viskoelastik yang melewati permukaan sebuah bola berpori. Permasalahan konveksi campuran atas sebuah bola berpori telah banyak dilakukan beberapa penelitian karena penerapannya yang luas dalam bidang teknik seperti mengurangi hambatan benda dan bahkan menghasilkan daya angkat yang cukup untuk menumpu benda pada kondisi tertentu.

Akhir - akhir ini, terdapat beberapa peneliti menyelidiki permasalahan aliran fluida yang melewati sebuah bola untuk berbagai jenis fluida. Molla, dkk (2005) meneliti tentang aliran konveksi bebas magnet dinamis pada bola dengan pembangkitan panas menggunakan metode kotak Keller. Amin, dkk (2002) meneliti aliran konveksi campuran dalam kondisi tunak (steady) dari fluida viskos tak mampu-mampat (incompressible) yang melewati sebuah 
Mohammad Tafrikhan ${ }^{1}$, Mohammad Ghani ${ }^{2}$ : Profil Kecepatan dan Temperatur .....

bola pejal dengan temperatur konstan. Akhter dan Alim (2008) meneliti pengaruh radiasi pada aliran konveksi bebas yang melewati sebuah bola dengan fluks panas permukaan yang seragam. Kasim (2014) meneliti tentang aliran konveksi campuran dalam kondisi tunak (steady) dari fluida viskoelastik tak mampu-mampat (incompressible) yang melewati permukaan sebuah bola dengan penyelesaian numerik metode kotak Keller. Namun, permasalahan aliran konveksi campuran dalam kondisi tak-tunak (steady state) dari fluida viskoelastik mampu-mampat (compressible) dengan penyelesaian numerik metode beda hingga Keller-Box belum banyak yang meneliti. Dalam makalah ini, dianalisa pengaruh parameter hidrodinamika magnet $(M)$ pada karakteristik profil kecepatan $\left(f^{\prime}\right)$, dan profil temperatur $(\theta)$. Aliran fluida konveksi campuran yang mengalir pada suatu bola berpori membentuk suatu lapisan batas lingkaran seperti yang ditunjukkan pada Gambar 1, dengan a merupakan jari - jari bola berpori.

\section{METODE PENELITIAN}

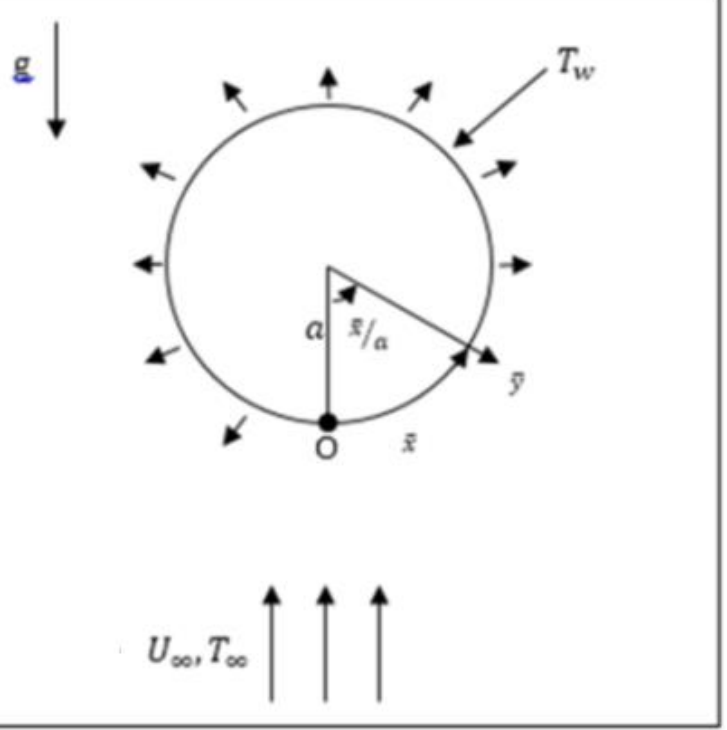

\section{Gambar 1. Aliran konveksi campuran yang melewati permukaan sebuah bola berpori}

Gambar 1 adalah arah aliran konveksi campuran yang melewati permukaan sebuah bola berpori secara vertikal dan lateral dengan laju fluida viskoelastik sebesar $U_{\infty}$ dan temperatur fluida viskoelastik sebesar $T_{\infty}$. Titik $O$ merupakan titik stagnasi, dengan kondisi saat $\bar{x}=0$ dan $\bar{y}=0$ sehingga laju fluida pada permukaan sebuah bola saat kondisi tersebut adalah $\bar{u}=$ 0 dan $\bar{v}=0$. Laju aliran fluida viskoelastik di sepanjang permukaan sebuah bola pada saat 
posisi dan waktu tertentu membentuk sudut sebesar $(\bar{x} / a)$ dan $\bar{r}$, dengan $\bar{r}$ merupakan jarak dari sumbu simetris terhadap permukaan sebuah bola. Dalam makalah ini, separasi pada posisi dan waktu tertentu dari aliran fluida viskoelastik yang melawan gaya gesek dianalisa. Separasi dapat menyebabkan momentum aliran fluida viskoelastik berkurang. Sehingga ketika aliran fluida viskoelastik mempunyai momentum yang kecil, hal tersebut dapat menyebabkan aliran fluida viskoelastik berbalik arah. Gaya luar dalam aliran konveksi campuran menyebabkan momentum yang dihasilkan dari fluida viskoelastik semakin besar. Gaya gesek antara permukaan sebuah bola dengan aliran fluida viskoelastik menyebabkan terjadinya perubahan nilai energi yang semakin berkurang. Selanjutnya, penurunan persamaan kontinuitas, momentum, dan energi dijelaskan secara detail pada pembahasan subbab selanjutnya.

\section{Persamaan Kontinuitas}

Laju perubahan terhadap waktu dari massa sistem yang berimpit = Laju perubahan terhadap waktu dari massa dari kandungan volume atur + Laju aliran netto dari massa melalui permukaan atur $=0$. Sesuai fenomena aliran konveksi bebas fluida viskoelastik yang melewati permukaan sebuah bola dalam kondisi incompressible, dapat dikontruksi persamaan kontinuitas dalam bentuk dimensi sebagai berikut:

$$
\frac{\partial}{\partial \bar{x}}(\bar{r} \bar{u})+\frac{\partial}{\partial \bar{y}}(\bar{r} \bar{v})=0
$$

dengan $\bar{r}=a \sin \left(\frac{\bar{x}}{a}\right)$ merupakan jarak radial dari bola berpori.

\section{Persamaan Momentum}

Laju perubahan terhadap waktu dari momentum sistem = Laju perubahan terhadap waktu dari momentum kandungan volume atur + Laju aliran netto dari momentum melewati permukaan atur = Jumlah dari gaya-gaya luar yang bekerja pada sistem. Sehingga persmaan momentum diperoleh:

$$
\begin{aligned}
\bar{u} \frac{\partial \bar{u}}{\partial \bar{x}}+\bar{v} \frac{\partial \bar{u}}{\partial \bar{y}}= & v\left[\frac{\partial^{2} \bar{u}}{\partial^{2} \bar{y}}\right]+g \beta\left(T-T_{\infty}\right) \sin \left(\frac{\bar{x}}{a}\right) \\
& -\frac{k_{0}}{\rho}\left[\bar{u}\left(\frac{\partial^{3} \bar{u}}{\partial \bar{x} \partial \bar{y}^{2}}\right)+\bar{v} \frac{\partial^{3} \bar{u}}{\partial \bar{y}^{3}}-\bar{v} \frac{\partial \bar{u}}{\partial \bar{y}}\left(\frac{\partial^{2} \bar{u}}{\partial \bar{y} \partial \bar{x}}\right)+\frac{\partial \bar{u}}{\partial \bar{x}}\left(\frac{\partial^{2} \bar{u}}{\partial \bar{y}^{2}}\right)\right]-\frac{v}{K^{*}} \bar{u} \\
& -\frac{1}{\rho} \sigma(\bar{u} \\
& \left.-\bar{u}_{e}\right) B_{0}^{2}
\end{aligned}
$$

dan persamaan energy:

$$
\bar{u} \frac{\partial \bar{T}}{\partial \bar{x}}+\bar{v} \frac{\partial \bar{T}}{\partial \bar{y}}=\alpha \bar{v} \frac{\partial^{2} \bar{T}}{\partial \bar{y}^{2}}
$$

dengan kondisi batas: 
Mohammad Tafrikhan ${ }^{1}$, Mohammad Ghani ${ }^{2}$ Profil Kecepatan dan Temperatur .....

$$
\begin{array}{cc}
\bar{u}=\bar{v}=0, \quad \frac{\partial \bar{T}}{\partial \bar{y}}=-\frac{q_{w}}{k} & \text { pada } \bar{y}=0, \\
\bar{u}=0, \frac{\partial \bar{u}}{\partial \bar{y}}=0, T-T_{\infty}, & \text { sebagai } \bar{y} \rightarrow \infty .
\end{array}
$$

\section{Model Matematika dalam Bentuk Non-Dimensi}

Selanjutnya, dengan menggunakan variabel berikut ini:

$$
\begin{gathered}
x=\frac{\bar{x}}{a}, y=R_{e}^{\frac{1}{2}}\left(\frac{\bar{y}}{a}\right), r(x)=\frac{\bar{r}(\bar{x})}{a}, u=\frac{\bar{u}}{U_{\infty}}, v=R_{e}^{\frac{1}{2}}\left(\frac{\bar{v}}{U_{\infty}}\right), \theta=\frac{R_{e}^{\frac{1}{2}}\left(T-T_{\infty}\right) k}{q_{w} a}, \\
u_{e}(x)=\frac{\overline{u_{e}}(\bar{x})}{U_{\infty}}
\end{gathered}
$$

maka persamaan (1), (2), dan (3) menjadi:

$$
\begin{gathered}
\frac{\partial}{\partial \bar{x}}(u r)+\frac{\partial}{\partial \bar{y}}(r v)=0 \\
u \frac{\partial u}{\partial x}+v \frac{\partial u}{\partial y}=u_{e} \frac{\partial u_{e}}{\partial x}+\frac{\partial^{2} u}{\partial y^{2}}+K\left[\frac{\partial}{\partial x}\left(u \frac{\partial^{2} u}{\partial y^{2}}\right)+v \frac{\partial^{3} u}{\partial y^{3}}-\frac{\partial u}{\partial y} \frac{\partial^{2} u}{\partial y^{2}}\right] \\
+\lambda \theta \sin (x)-M\left(u-u_{e}\right)-P u \\
u \frac{\partial \theta}{\partial x}+v \frac{\partial \theta}{\partial y}=\frac{1}{P r} \frac{\partial^{2} \theta}{\partial y^{2}}
\end{gathered}
$$

dengan $\lambda=\frac{G_{r}}{R e^{\frac{5}{2}}}, P=\left(\frac{k}{g \beta T_{w}}\right)^{\frac{1}{2}} \frac{v}{K^{*}}$ berturut-turut adalah parameter konveksi campuran dan porositas, sedangkan kondisi batas menjadi:

$$
\begin{gathered}
u=v=0 \quad \theta^{\prime}=-1 \quad \text { pada } y=0, \\
u=0, \frac{\partial \bar{u}}{\partial \bar{y}}=0, \theta=0, y \rightarrow \infty .
\end{gathered}
$$

Persamaan (4), (5), dan (6) disebut sebagai model matematika dalam bentuk non -dimensi.

\section{Prosedur penyederhanaan Model menggunakan Stream Function}

Dengan menggunakan:

$$
\psi=x r(x) f(x, y), \theta=\theta(x, y)
$$

maka:

$$
u=\frac{1}{r} \frac{\partial \psi}{\partial y} \quad \text { dan } \quad v=-\frac{1}{r} \frac{\partial \psi}{\partial x}
$$

Kemudian disubstitusikan ke model dalam bentuk non-dimensi sebelumnya, didapat:

$$
\begin{aligned}
& \frac{\partial^{3} f}{\partial y^{3}}-\left(\frac{\partial f}{\partial y}\right)^{2}+\frac{9}{4} \frac{\sin x \cos x}{x}+\left(1+x \frac{\cos x}{\sin x}\right) f \frac{\partial^{2} f}{\partial y^{2}}+\lambda \theta \frac{\sin x}{x} \\
& +K\left[2 \frac{\partial f}{\partial y} \frac{\partial^{3} f}{\partial y^{3}}-\left(1+x \frac{\cos x}{\sin x}\right)\left(f \frac{\partial^{4} f}{\partial y^{4}}+\left(\frac{\partial^{2} f}{\partial y^{2}}\right)^{2}\right)\right]
\end{aligned}
$$




$$
\begin{aligned}
= & K x\left[\frac{\partial f}{\partial x} \frac{\partial^{4} f}{\partial y^{4}}-\frac{\partial^{2} f}{\partial x \partial y} \frac{\partial^{3} f}{\partial y^{3}}-\frac{\partial f}{\partial y} \frac{\partial^{4} f}{\partial x \partial y^{3}}+\frac{\partial^{2} f}{\partial y^{2}} \frac{\partial^{3} f}{\partial x \partial y^{2}}\right] \\
+ & x\left(\frac{\partial f}{\partial y} \frac{\partial^{2} f}{\partial x \partial y}-\frac{\partial f}{\partial x} \frac{\partial^{2} f}{\partial y^{2}}\right)-P \frac{\partial f}{\partial y}+\frac{3}{2} M \frac{\sin x}{x} \\
& -M \frac{\partial f}{\partial y} \\
& \frac{1}{\operatorname{Pr}} \frac{\partial^{2} \theta}{\partial y^{2}}+\left(1+x \frac{\cos x}{\sin x}\right) f \frac{\partial \theta}{\partial y} \\
= & x\left(\frac{\partial f}{\partial y} \frac{\partial \theta}{\partial x}-\frac{\partial f}{\partial x} \frac{\partial \theta}{\partial y}\right),
\end{aligned}
$$

dengan kondisi batas:

$$
\begin{gathered}
f=0, \frac{\partial f}{\partial y}=0, \quad \theta^{\prime}=-1 \text { pada } y=0 \\
\frac{\partial f}{\partial y} \rightarrow \frac{3}{2} \frac{\sin x}{x}, \quad \frac{\partial^{2} f}{\partial y^{2}}=0, \quad \theta \rightarrow 0 \text { pada } y \rightarrow \infty .
\end{gathered}
$$

Pada saat $\mathrm{x} \rightarrow 0$, maka model matematika menjadi:

$$
\begin{gathered}
f^{\prime \prime \prime}+2 f f^{\prime \prime}-f^{\prime 2}+\frac{9}{4}+\lambda \theta+2 K\left(f^{\prime} f^{\prime \prime \prime}-f f^{\prime \prime \prime \prime}-f^{\prime \prime 2}\right)-M\left(f^{\prime}-\frac{3}{2}\right)-P f^{\prime}=0, \\
\frac{1}{P r} \theta^{\prime \prime}+2 f \theta^{\prime}=0,
\end{gathered}
$$

dengan kondisi batas:

$$
\begin{aligned}
& f(0)=f^{\prime}(0)=0, \quad \theta^{\prime}(0)=-1 \\
& f^{\prime}(\infty)=\frac{3}{2}, f^{\prime \prime}(\infty)=0, \theta(\infty)=0 .
\end{aligned}
$$

\section{HASIL PENELITIAN DAN PEMBAHASAN}

Solusi numerik pada aliran konveksi campuran yang melalui bola berongga dengan pengaruh hidrodinamika magnet dapat diselesaikan dengan cara diskritisasi persamaan stream function menggunakan metode beda hingga Keller-Box. Hasil diskritisasi, kemudian disimulasikan dengan menggunakan software MATLAB R2010a dan diperoleh profil kecepatan fluida $(f)$, dan profil temperatur $(\theta)$ dengan pengaruh parameter hidrodinamika magnet $(M)$.

Algoritma Keller-Box untuk kasus aliran konveksi campuran yang melalui bola berpori dengan pengaruh hidrodinamika magnet, dapat dituliskan sebagai berikut:

\footnotetext{
input : inisialisasi nilai bilangan Prandtl $\left(P_{r}\right)$, parameter viskoelastik $(K)$, parameter konveksi campuran ( $\lambda)$, hidrodinamika magnet $(M)$, boundary layer thickness $y$, step size $h$
} 
Mohammad Tafrikhan ${ }^{1}$, Mohammad Ghani ${ }^{2}$ : Profil Kecepatan dan Temperatur .....

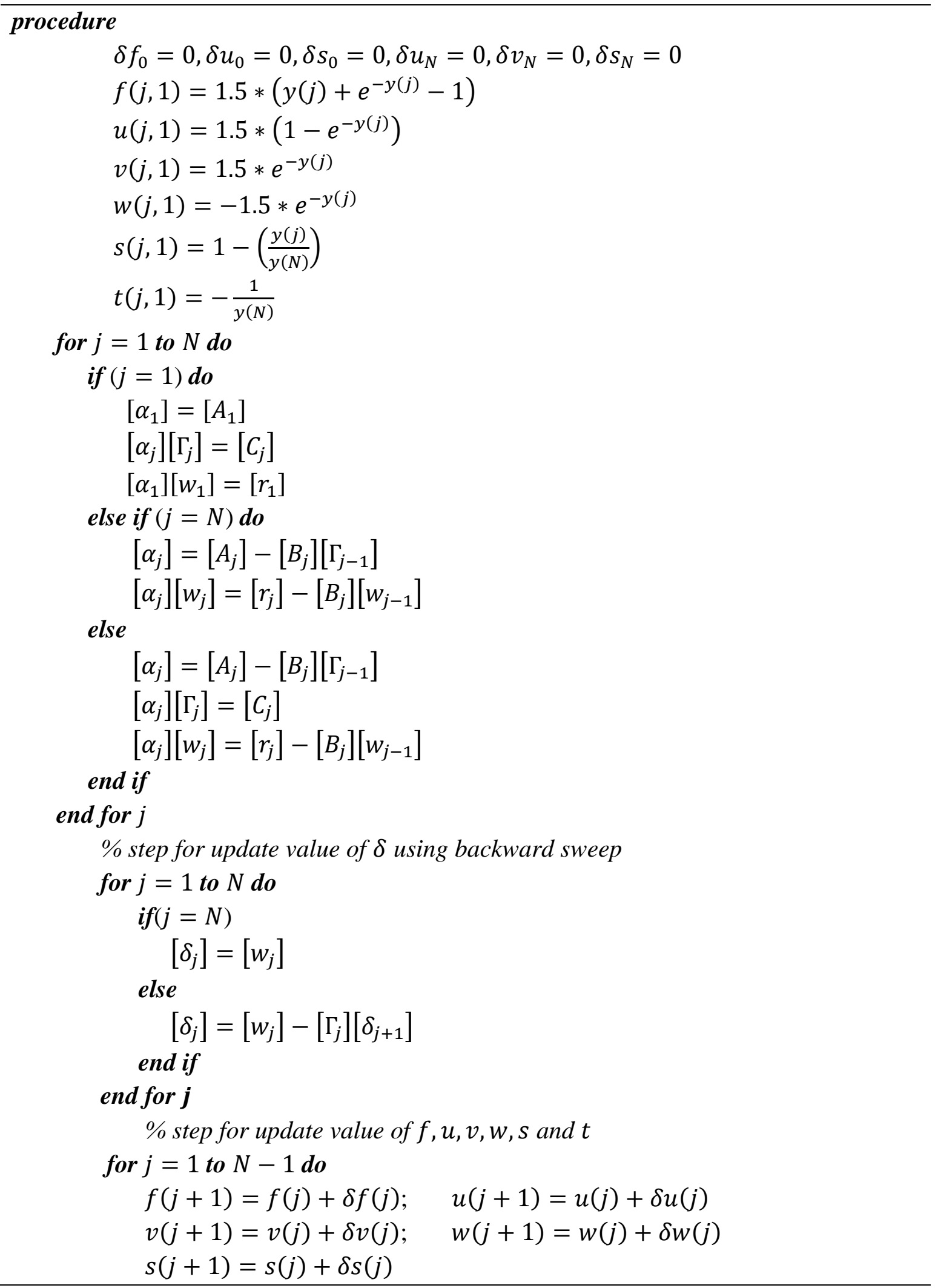




$$
\begin{aligned}
& t(j+1)=t(j)+\delta t(j) \\
& \text { end for } j
\end{aligned}
$$

\section{end procedure}

Output : profil kecepatan $\left(f^{\prime}\right)$, profil temperatur $(\theta)$

Selanjutnya, stensil metode beda hingga Keller-Box dalam kondisi tunak (steady state) direpresentasikan pada gambar berikut:

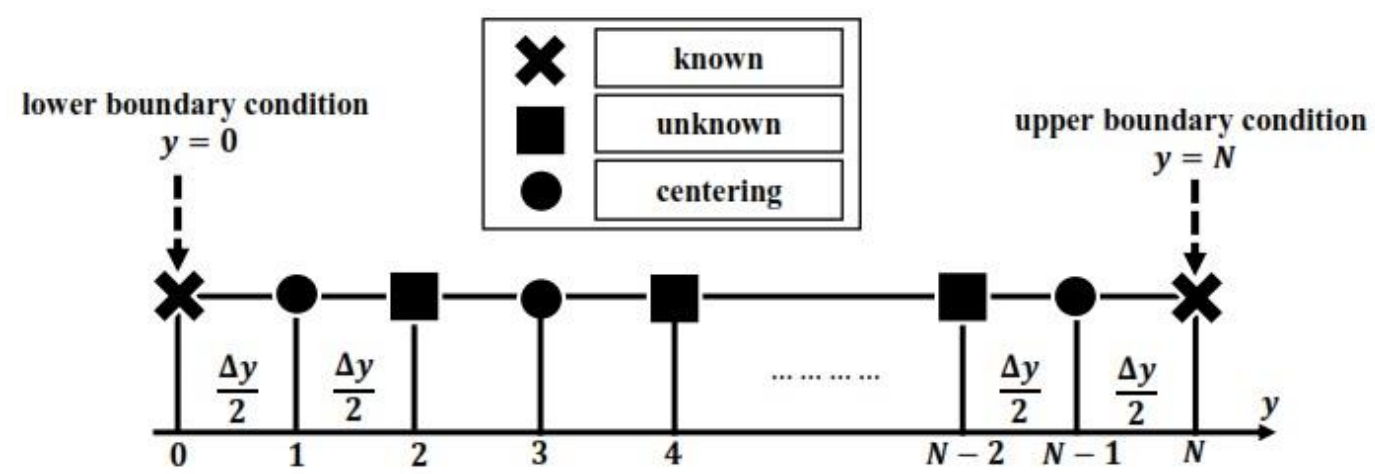

Gambar 2. Stensil metode beda hingga Keller-Box dengan kondisi tunak (steady state)

Gambar 2 menjelaskan stensil dari metode beda hingga Box-Keller dengan kondisi tunak (steady state) dengan nilai step size $\frac{\Delta y}{2}$, kondisi batas bawah saat $y=0$ dan kondisi batas atas saat $y=N$, sedangkan $y$ adalah ketebalan lapisan batas yang terbentuk dari tegangan geser antara fluida viskoelastik dengan permukaan bola berpori.

Berdasarkan kondisi tersebut, maka persamaan stream function yang sudah diperoleh sebelumnya, terlebih dahulu diubah kedalam bentuk ke order satu seperti yang dituliskan sebagai berikut.

$$
\begin{aligned}
f^{\prime} & =u \\
u^{\prime} & =v \\
v^{\prime} & =w \\
s^{\prime} & =t \\
w+2 f v-u^{2}+\frac{9}{4}+\lambda s+2 K(u w- & \left.f w^{\prime}-v^{2}\right)-M\left(u-\frac{3}{2}\right)-P u=0 \\
\frac{1}{P_{r}} t^{\prime}+2 f t & =0
\end{aligned}
$$

dengan $s$ adalah bentuk penulisan lain dari $\theta$ dan kondisi batas sebagai berikut.

$$
f(0)=u(0)=0, t(0)=-1 \text { pada } y=0
$$


Mohammad Tafrikhan ${ }^{1}$, Mohammad Ghani ${ }^{2}$ : Profil Kecepatan dan Temperatur .....

$$
u \rightarrow \frac{3}{2}, v=0, s \rightarrow 0 \text { pada } y \rightarrow \infty
$$

Selanjutnya, persamaan (10) - (15) dinyatakan dalam bentuk vektor matriks, dan diselesaikan dengan menggunakan dekomposisi LU (lower, upper). Hasil numerik profil kecepatan dan temperatur pada aliran konveksi campuran dengan pengaruh dengan pengaruh parameter hidrodinamika magnet $(M)$ adalah sebagai berikut:
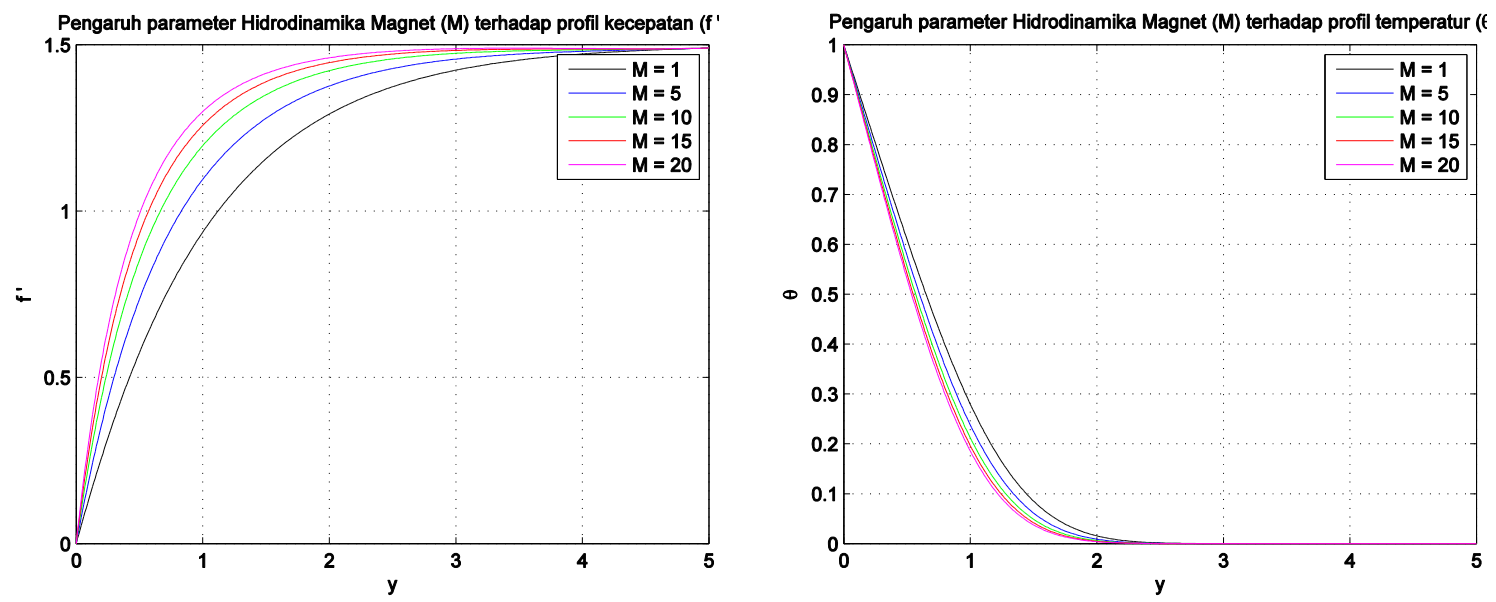

\section{Gambar 3. Profil kecepatan $\left(f^{\prime}\right)$ dan temperatur $(\theta)$ dengan pengaruh hidrodinamika magnet $(M)$}

Gambar 3 tampak bahwa semakin meningkat parameter hidrodinamika magnet $(M=$ $1, M=5, M=10, M=15, M=20$ ) maka semakin besar kecepatan aliran fluida di setiap titik $y$ tertentu, hal ini dikarenakan pengaruh densitas dari fluida viskoelastik yang semakin menurun seperti yang ditunjukkan dengan korelasi $M=\frac{\sigma \mathrm{B}_{0} a}{\rho U_{\infty}}$. Densitas yang menurun menyebabkan gaya apung yang bekerja semakin besar, sehingga menyebabkan kecepatan semakin besar di setiap titik $y$ tertentu.

Selanjutnya, profil temperatur fluida viskoelastik $(\theta)$ dengan nilai parameter hidrodinamika magnet $(M=1, M=5, M=10, M=15, M=20)$ untuk bilangan Prandtl $P_{r}=1, \lambda=1$, dan $K=1$. Gambar 3 tampak bahwa semakin meningkat parameter hidrodinamika magnet, maka temperatur semakin kecil di setiap titik $y$ tertentu, hal ini dikarenakan suatu korelasi antara parameter hidrodinamika magnet berbanding terbalik dengan kecepatan fluida $U_{\infty}$ seperti yang dituliskan sebagai berikut.

$$
M=\frac{\sigma B_{0} a}{\rho U_{\infty}}
$$

Sehingga hal tersebut menyebabkan temperatur fluida viskoelastik yang melewati permukaan bola semakin kecil di setiap titik $y$ tertentu. 


\section{KESIMPULAN, DISKUSI DAN REKOMENDASI}

Simpulan dari penelitian ini adalah semakin meningkat parameter hidrodinamika magnet $(M=1, M=5, M=10, M=15, M=20)$ maka semakin besar kecepatan aliran fluida di setiap titik $y$ tertentu, hal ini dikarenakan pengaruh densitas dari fluida viskoelastik yang semakin menurun seperti yang ditunjukkan dengan korelasi $M=\frac{\sigma \mathrm{B}_{0} a}{\rho U_{\infty}}$. Kemudian, semakin meningkat parameter hidrodinamika magnet, maka temperatur semakin kecil di setiap titik $y$ tertentu, hal ini dikarenakan suatu korelasi antara parameter hidrodinamika magnet berbanding terbalik dengan kecepatan fluida $U_{\infty}$.

\section{DAFTAR PUSTAKA}

Causon, D.M. dan Mingham, C.G. (2010). Introductory Finite Difference Methods for PDEs, Departement Of Computing and Mathematics, UK.

Hakim, Imansyah I. (2012), Fenomena Thermophoresis Dan Pemanfaatannya Sebagai Thermal Precipitator Untuk Meningkatkan Kebersihan Udara, Disertasi Doktor, Universitas Indonesia, Depok.

Hoffmann, Klaus A. dan Chiang, Steve T. (2000), Computational Fluid Dynamics, Engeneering Education System, USA.

Kasim, A.R.M. (2014), Convective Boundary Flow of Viscoelastic Fluid, Disertasi Ph.D., Universiti Teknologi Malaysia, Malaysia.

Kreith, Frank. (1994), Prinsip-Prinsip Perpindahan Panas, Edisi Ketiga, Erlangga, Jakarta. Potter, Merlec C. dan Wiggert, David C. (2008). Mekanika Fluida, Erlangga, Jakarta.

Salleh, M. Z. dan Nazar, R. (2010), Modeling of Free Convection Boundary Layer Flow on a Sphere with Newtonian Heating, Acta Appl. Math., 112: 263-274.

Streeter, Victor L., Wyle, E. Benjamin, dan Prijno, Arko. (1988), Mekanika Fluida, Edisi Delapan, Erlangga, Jakarta.

Widodo, Basuki. (2012), Pemodelan Matematika, Itspress, Surabaya. 